\title{
PENGARUH UMUR PEMOTONGAN DAN LEVEL PUPUK ORGANIK TERHADAP PERTUMBUHAN VEGETATIF RUMPUT BRACHIARIA HUMIDICOLA (Studi Kasus Di Laboratorium Agrostologi Fakultas Peternakan Universitas Sam Ratulangi Manado)
}

\section{Dodit Kurniawan; Selvie D. Anis* ,Rustandi , W. B. Kaunang}

Fakultas Peternakan Universitas Sam Ratulangi, 95115

\begin{abstract}
ABSTRAK
Rumput Brachiaria humidicola (Brahum) adalah salah satu jenis hijauan yang dimanfaatkan sebagai pakan. Rumput Brahum tergolong tanaman rumput tahunan yang mempunyai banyak stolon dan rizoma serta membentuk lapisan penutup tanah yang padat. Batang vegetatifnya bertumbuh merambat dan mengeluarkan akar dari bagian tanah bawah. Dari sudut pandang agrostologi Brahum dikategorikan sebagai tanaman budidaya dan bukan sebagai gulma, sehingga memerlukan manajen yang tepat. Defoliasi adalah pemotongan yang dilakukan oleh manusia atau perengutan oleh ternak pada satu areal padang rumput penggembalan.

Penelitian ini bertujuan mengkaji pengaruh perlakuan umur pemotongan dan level pupuk organik terhadap pertumbuhan vegetatif Brahum. Perlakuan yang diuji terdiri dari umur potong 30 hari dan 40 hari dengan level pupuk organik $\mathrm{P} 1=0$ gram, P2=400 gram, P3=800 gram dan $\mathrm{P} 4=1200$ gram/polybag. Variabel yang diukur terdiri dari jumlah stolon, panjang stolon dan jumlah anakan. Percoban ini menggunakan pola faktorial $2 \times 4$ dengan rancangan acak dasar Acak lengkap yang diulang sebanyak 4 kali.

Hasil penelitian menunjukan bahwa interaksi perlakuan berpengaruh nyata terhadap variabel yang diuji, dan yang terbaik diperoleh pada interaksi perlakuan umur potong 40 hari (D2) dengan level pupuk 400 gram /polibag (P2).
\end{abstract}

*Korespondensi (corresponding Author)

Email: selvie_anis@yahoo.com
Dari hasil penelitian disimpulkan bahwa untuk mendapatkan pertumbuhan vegetatif yang baik pada rumput $B$. humidicolla di pupuk dengan pupuk organik berasal dari feses ternak ayam petelur terbaik pada pemupupukan 400 gram/polibag dengan umur potong 40 hari setelah triming.

Kata Kunci : Umur Pemotongan, Pupuk Organik, Pertumbuhan Vegetatif, Brahum.

\section{ABSTRACT}

THE EFFECT OF CUTTING AGES AND LEVEL OF ORGANIC FERTILIZER ON VEGETATIVE GROWTH OF BRACHIARIA HUMIDICOLA (Case Study At Agrostology Laboratory Faculty Of Animal ScienceSam Ratulangi UniversityManado)

Brachiaria humidicola is a forages as animal feed. Defolation is a proces which is apart of vegetative removed by human or by grazing animals. Brahum is one of perenial species has stolon and has a good ground cover. From agrostology point of view Brahum needs a good agronomic management and it is not as weeds species.

The aim of this experiment to asses the effect of defolition and level of organic fertilizer on vegetative growth of Brahum Treatments consist of ages of cutting of 30 day and 40 day after triming, and level of organic fertilizer of $\mathrm{P} 1=0 \mathrm{gr} ; \mathrm{P} 2=400 \mathrm{gr}$; P3=800 gr; P4=1200 gr/polybag. Variable measured was the number of stolon, long of stolon and number of tiller. Treatment was arranged factorial $2 \times 4$ based on completly randomized design (RAL) with 4 replication. 
The results of this research show that the interaction of treatments significandtly effected on all variabel measured, and the best result found at interaction between cutting ages 40 day and level of organic fertilizer $400 \mathrm{gr} /$ polybag. Based on this result it could be concluded that do get the best performance of Brahum need to cut at 40 days regrowth and dosis of organic fertilizer by 400 gr/polybag.

Keywords : Age of cutting, organic fertilizer, Vegetative growth, Brahum

\section{PENDAHULUAN}

Dalam usaha perternakan khususnya sapi potong, hijauan merupakan pakan utamanyayang harus tersedia sepanjang tahun dan mempunyai kualitas yang baik sehingga usaha tersebut diharapkan dapat berkembang. Hijauan segar adalah rumputataulegum pakan yang diberikan kepada ternak dalam bentuk segar, baik yang dipotong terlebih dahulu dan diberikan kepada ternak di kandang atau yang direnggut oleh ternak di padang penggembalaan.

Rumput Brachiaria humidicola (Brahum) adalah salah satu jenis hijauan yang dimanfaatkan sebagai pakan. Brahummerupakan hijauan yang palatabel, memilikitingkatpersistensi yang baikdan dapat digunakan sebagai rumput potongan atau rumput penggembalaan. Produksi yang optimal dapat dicapaidengan tambahan unsur hara nitrogen yang biasanya diperoleh dengan menggunakan pupuk sintetik atau pupuk anorganik dalam bentuk urea. Namun demikian karena permintaan jenis pupuk ini semakin banyakdan dikuti dengan harganya yang semakin mahal maka diperlukan alternatif lain seperti penggunaan pupuk organik. Pupuk organik adalah jenis pupuk yang terbuat dari bahan-bahan makhluk hidup seperti tanaman, sisa -sisa tanaman dan kotoran hewan.

Defoliasi adalah pemotongan yang dilakukan oleh manusia atau perenggutan oleh ternak pada satu areal padang rumput penggembalan. Interval atau umur pemotongan akan berpengaruh pada pertumbuhan kembali hijauan pakan, selanjutnya pada jumlah produksi dan kualitasnya, oleh karena itu pengaturan interval pemotongan sangat diperlukan dalam tatalaksana padang rumput.

Berdasarkan latar belakang diatas maka dilakukan penelitian untuk mengamati dan mempelajari pengaruh umur pemotongan dan pemberian pupuk organik bokasi kotoran ayam terhadap pertumbuhan vegetatif rumput Brachiariahumidicola

\section{METODOLOGI PENELITIAN}

Penelitian ini dilaksanakan di Laboratorium Agrostologi Fakultas Peternakan UNSRAT Manado di mulai sejak bulan September 2016 - Januari 2017.

Bahan yang digunakan dalam penelitian ini adalah anakan rumput Brahum, 
unsurhara makro (NPK) sebagai pupuk dasar.Alat yang digunakan adalah gunting, pisau, cangkul, polybag, meteran dan spidol.

Dalam percobaan tanaman ditanam dalam polly-bag berdiameter $30 \mathrm{Cm}$. Tanah yang digunakan diambil dari lahan yang sudah 2 tahun ditumbuhi rumput Brahum. Perlakuan yang akan diuji sebagai berikut:

1. Perlakuan defoliasidalam hal ini umur pemotongan sebagai faktor $\boldsymbol{A}$ terdiri dari: D1 defoliasi 30 hari dan D2 Defoliasi 40 hari

2. Perlakuan level pupuk organik sebagai faktor $\boldsymbol{B}$ terdiri dari:P1.0 gram;P2.
400 gram;P3. 800gram; danP4. 1200 gram/polybag.

Oleh karena daya larut pupuk organik lambat, dan untuk mencegah defisiensi pada pertumbuhan awal, semua media tumbuh diberikan pupuk dasar majemuk NPK dalam jumlah yang sama sebanyak 10 gram per poly-bag.

Perlakuan ini diatur secara faktorial $2 \times 4$ dalam rancangan Acak Lengkap (RAL) dengan 4 ulangan. (Gomez and Gomez, 1995),sehingga terdapat 32 polybag / unit percobaan. Semua perlakuan diatur secara acak. Hasil pengacakan terlihat pada gambar1

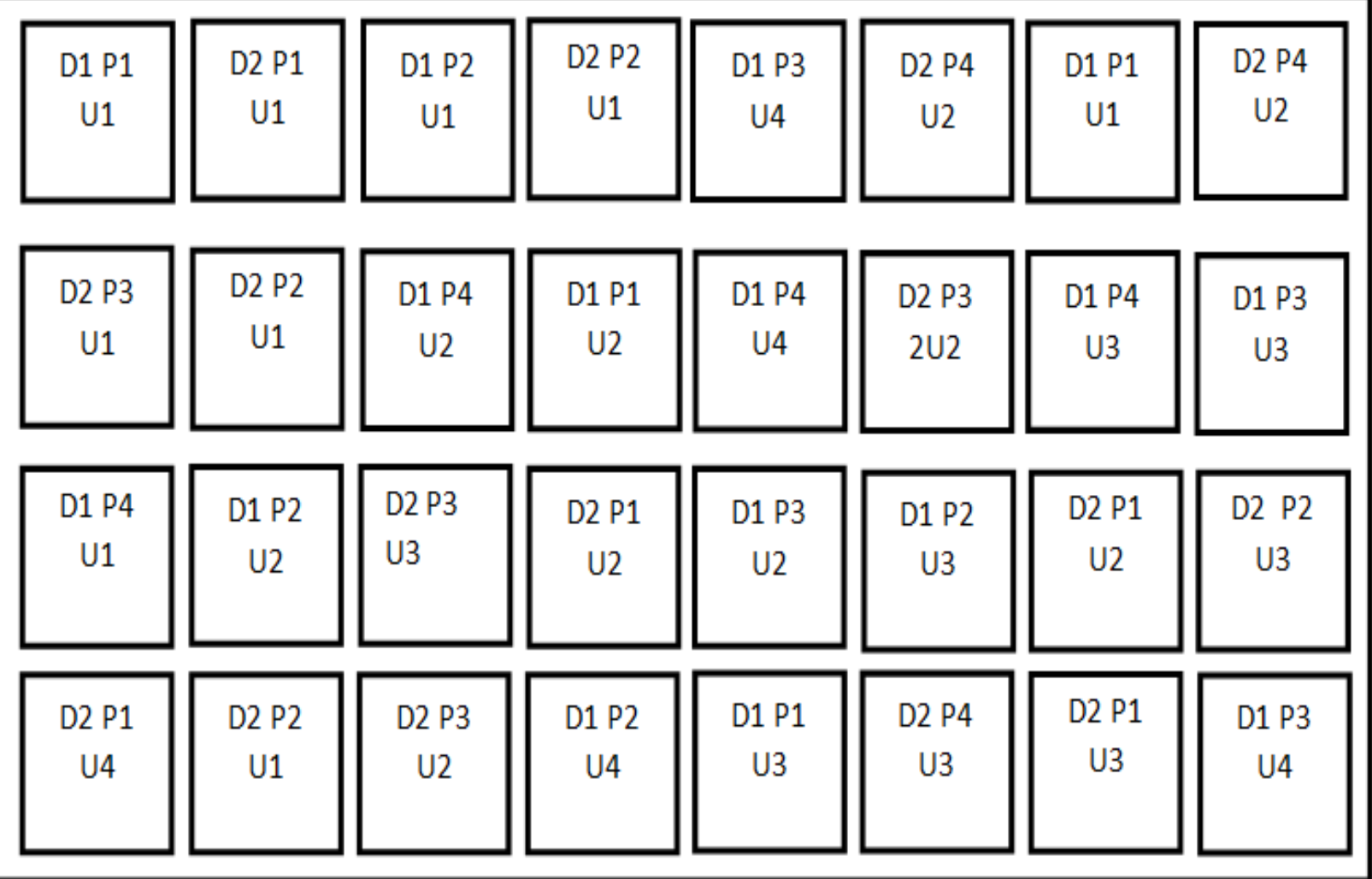

Gambar 1: Penelitian Pengaruh Umur Pemotongan dan Level Pupuk Organik Terhadap Pertumbuhan Vegetatif RumputBrahum 


\section{HASIL DAN PEMBAHASAN}

\section{Jumlah Stolon}

Tabel 2. Pengaruh Umur Pemotongan dan Level Pupuk Organik Terhadap Jumlah Stolon, Panjang Stolon, Jumlah Anakan Brahum.

\begin{tabular}{cccc}
\hline Faktor & Jumlah Stolon & Panjang Stolon & Jumlah Anakan \\
\hline D1 P1 & $9,25^{\mathrm{bc}}$ & $49,5^{\mathrm{ab}}$ & $13,0^{\mathrm{b}}$ \\
D1 P2 & $12,25^{\mathrm{bc}}$ & $67,5^{\mathrm{ab}}$ & $12,50^{\mathrm{b}}$ \\
D1 P3 & $9,25^{\mathrm{bc}}$ & $37,0^{\mathrm{bc}}$ & $13,75^{\mathrm{b}}$ \\
D1 P4 & $3,00^{\mathrm{c}}$ & $33,75^{\mathrm{d}}$ & $5,00^{\mathrm{b}}$ \\
D2 P1 & $10,25^{\mathrm{bc}}$ & $59,5^{\mathrm{ab}}$ & $11,50^{\mathrm{b}}$ \\
D2 P2 & $20,25^{\mathrm{a}}$ & $91,0^{\mathrm{a}}$ & $28,00^{\mathrm{a}}$ \\
D2 P3 & $8,00^{\mathrm{bc}}$ & $56,5^{\mathrm{ab}}$ & $7,25^{\mathrm{b}}$ \\
D2 P4 & $4,00^{\mathrm{c}}$ & $36,25^{\mathrm{c}}$ & $5,00^{\mathrm{b}}$
\end{tabular}

Ket: Nilai yang di ikuti dengan superskrip yang berbeda pada kolom yang sama menunjukkan perbedanyang nyata $(\mathrm{p}<0,05)$

Hasil analisis keragaman menunjukkan bahwa umur pemotongan dan level pupuk organik memberikan pengaruh yang berbeda nyata $(\mathrm{p}<0,05)$ demikian juga interaksi antara keduanya memberikan pengaruh yang berbeda nyata $(\mathrm{p}<0,05)$ terhadap jumlah stolon. Hasil uji lanjut (Tabel 2) dengan menggunakan Tukey Simultaneus Test menunjukkan bahwa interaksi perlakuan umur potong 30 hari dengan pemupukan 0 gram (D1P1), umur potong 30 hari dengan pemupukan 400 gram(D1P2), umur potong 30 hari dengan pemupukan 800 gram ( D1P3) dan umur potong 30 hari dengan pemupukan 1200 gram (D1P4), memberikan pengaruh yang tidak berbeda nyata $(\mathrm{P}>0,05)$ tetapi berbeda nyata dengan umur potong 40 hari dengan pemupukan 400 gram (D2P2) $(\mathrm{P}<0,05)$. Jumlah stolon terbanyak diperoleh pada interaksi perlakuan D2P2 yaitu sebanyak 20,25 stolon dan berbeda nyata $(\mathrm{P}<0,05)$ dengan interaksi lainnya. Hal ini mengartikan bahwa untuk mendapatkan jumlah stolon terbaik dalam penelitian ini digunakan pupuk organik maksimal 400 gram/polibag dengan umur pemotongan 40 hari. Hubungan antara jumlah stolon dan level pupuk organik terlihat pada Garafik 1 


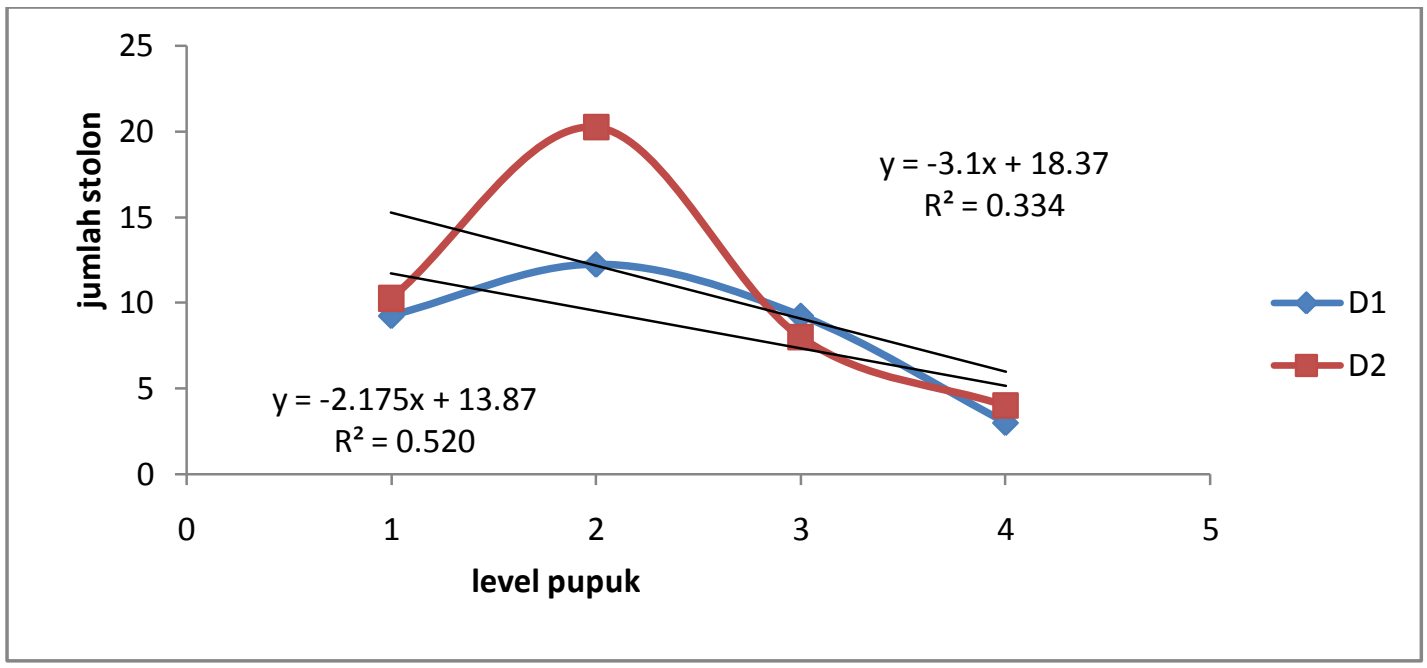

Grafik 1. Hubungan Level Pupuk Organik Dengan Jumlah Stolon

Grafik 1 menunjukkan bahwa semakin tinggi level pupuk organik, jumlah stolon semakin menurun. Jumlah stolon meningkat hanya sampai pada level pupuk organik $400 \mathrm{gram} /$ polibag (P2) pada umur potong 30 dan 40 hari.

\section{Panjang Stolon}

Hasil penelitan pengaruh perlakuan umur pemotongan dan level pupuk organik terhadap variabel panjang stolon dapat dilihat pada Tabel 2. Hasil analisis keragaman menunjukkan adanya pengaruh interaksi antara umur pemotongan dengan pemberian level pupuk organik terhadap panjang stolon. Uji lanjut dengan mengunakan Tukey Simultaneus Tests menunjukkan interaksi perlakuan D1P1, D1P2, D1P3 dan D1 P4 memberikan pengaruh yang tidak berbeda nyata $(\mathrm{P}<0,05)$, tetapi berbeda nyata dengan $\mathrm{D} 2$ $\mathrm{P} 2(\mathrm{P}<0,05)$. Panjang stolon terbanyak di peroleh pada interaksi perlakuan D2 P2 sebanyak 91,00 $\mathrm{Cm}$ dan berbeda nyata $(\mathrm{P}<0,05)$ lebih tinggi dibanding interaksi perlakuan lainnya.

Hal ini mengartikan bahwa, untuk mendapatkan panjang stolon terbaik pupuk kandang yang digunakan maksimal 400 gram/polibag pada umur potong 40 hari. Hubungan antara panjang stolon dan level pupuk organik terlihat pada Garafik 2 di bawah ini. 


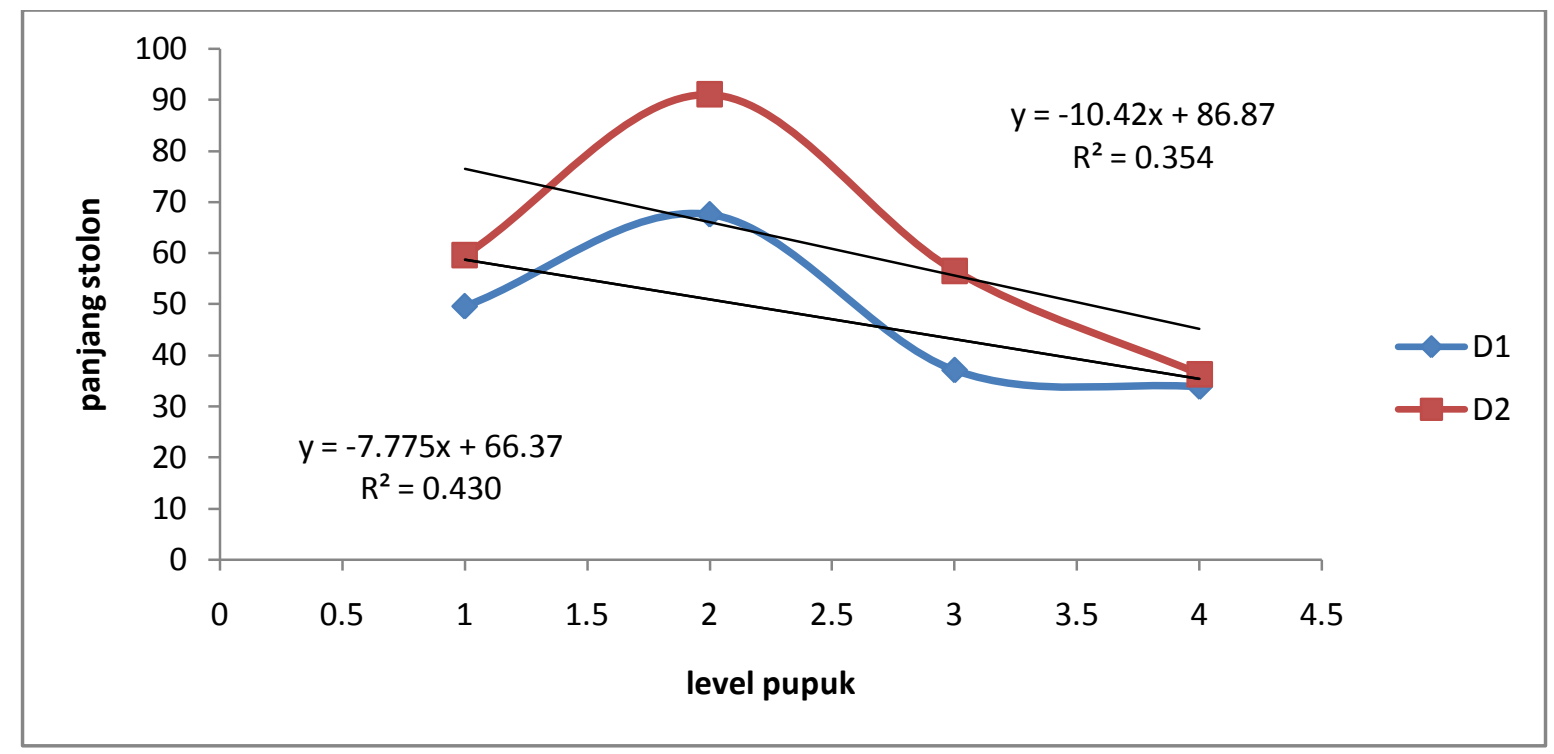

Grafik 2. Hubungan Level Pupuk Organik Dengan Panjang Stolon

Grafik 2 di atas menunjukkan bahwa semakin tinggi level pupuk organik, panjang stolon semakin menurun. Panjang stolon meningkat hanya sampai pada level pupuk organik 400 gram/ polibag (P2) pada umur potong 30 dan 40 hari.

\section{Jumlah Anakan}

Berdasarkan hasil analisis keragaman menunjukkan bahwa interaksi antara umur pemotongan dan level pupuk organik memberikan pengaruh yang berbeda nyata terhadap jumlah anakan $(\mathrm{P}<0,05)$. Hasil uji lanjut (Tabel 2) dengan menggunakan Tukey Simultaneus Test diperoleh hasil D1P1, D1P2, D1P3 dan D1P4, memberikan pengaruh yang tidak berbeda tidak nyata $(\mathrm{P}>0,05)$, tetapi berbeda nyata dengan D2P2 (P>0,05) .Jumlah anakan terbanyak diperoleh pada interaksi perlakuan D2 P2 sebanyak 28,00 anakan.
Hubungan antara panjang stolon dan level pupuk organik terlihat pada Grafik 3.

Penyajian Grafik 3 dimaksudkan untuk menunjukkan hubungan level pupuk kandang dengan variabel jumlah anakan. Terlihat jumlah anakan pada level pupuk 400 gram/polibag dan umur tanam 40 hari paling banyak dibandingkan dengan jumlah anakan pada umur tanaman 30 hari. Hasil penelitian menunjukkan bahwa pemberian dosis pupuk kotoran ternak ayam memberikan pengaruh terhadap jumlah anakan rumput Brahum umur 2 mst, 4 mst, 6 mst dan 8 mst. Pemberian dosis pupuk kotoran ayam 20 ton $\mathrm{ha}^{-1}, 30$ ton ha ${ }^{-1}$ dan 40 ton $\mathrm{ha}^{-1}$ memberikan pengaruh yang sama terhadap jumlah anakan dan produksi/bobot basah rumput Brahum, namun pada dosis 40 ton ha ${ }^{-1}$ memberikan hasil yang tinggi (Kusuma, 2015). 


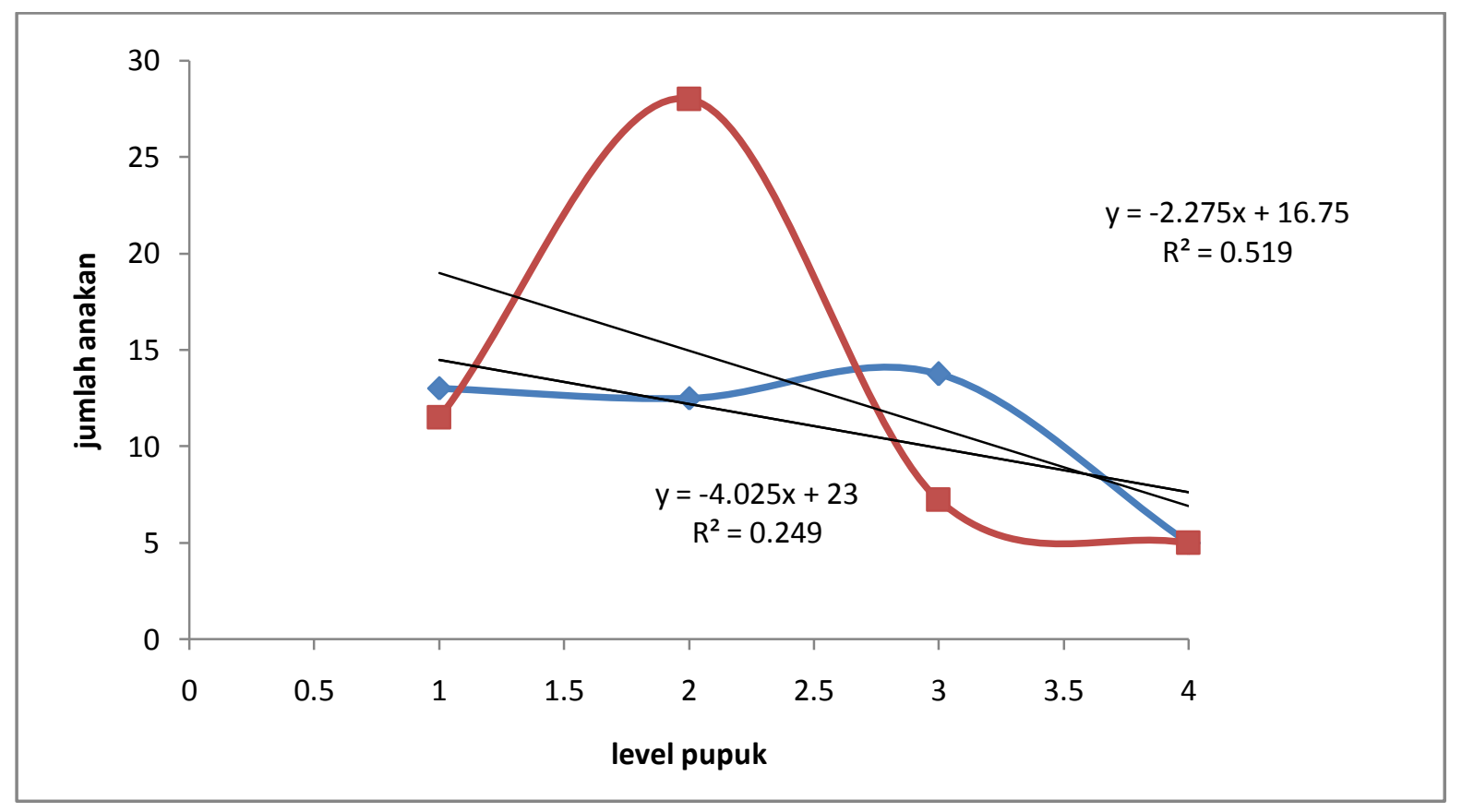

\section{Grafik 3. Hubungan Antara Level Pupuk Organik Dengan Jumlah Anakan}

Hasil ini sejalan dengan penelitian Budya

Satata (2014) yang mengatakan pemberian pupuk kotoran ternak memberikan pengaruh terhadap jumlah anakan rumput Brahum umur $4 \mathrm{mst}, 6 \mathrm{mst}$ dan $8 \mathrm{mst}$, tinggi tanaman umur 8 mst serta produksi tanaman/bobot basah tanaman.

Pengaruh perlakuan terhadap variabel jumlah stolon, panjang stolon dan jumlah anakan (Tabel 1), menunjukkan tanaman Brahum cv Tully memberikan respon yang sama, dimana interaksi perlakuan D2 P2 memberikan hasil yang terbaik terhadap ketiga variabel yang diukur. Semakin tinggi level pupuk, semakin menurun hasil yang diperoleh. Penurunan hasil mungkin disebabkan oleh $\mathrm{PH}$ tanah yang semakin basah $(\mathrm{PH}>7)$, sesuai dengan hasil analisis tanah.

Hasil analisis tanah menunjukkan bahwa pada level pupuk kandang 1200 gram/polibag PH tanah mencapai 7,69 (Lampiran 1), kendati rumput Brahuma tumbuh baik pada PH netral 6-7 (Tropical Forages).

Kemungkinan lain penyebab turunnya performans variable yang diamati dengan semakin tingginya level pupuk sampai 1200 gram/polibag, mungkin disebabkan oleh kandungan unsur fosfor (P) yang sangat tinggi banyak 1328 Ppm kelebihan unsur (P) dapat menghambat penyerapanunsur hara lain terutama unsur hara mikro. (Chotbang et al., 2008). 
Faisal (2013) menyatakan bahwa apabila unsur Fosfor (P) berlebihan maka tanaman akan menunjukkan gejala seperti kekurangan Nitrogen $(\mathrm{N})$ dimana tanaman menjadi kerdil dan warna daun menjadi kekuningan. Hal ini sejalan dengan hasil yang diperoleh di lapang bahwa pada pemupukan yang lebih dari 400 gram/polibag, tanaman menjadi kerdil, jumlah stolon, panjang stolon dan jumlah anakan sangat nyata lebih sedikit.

Dari hasil analisa tanah dilaboratorium pengujian balai penelitan tamaman palma Manado, terlihat semakin tinggi pupuk organik semakin tinggi pula kandungan fosfor (P205 tersedia) sebesar 1328 ppm demikian juga kandungan Kalium (K) sebesar $0,57 \%$.

\section{KESIMPULAN}

Dari hasil penelitian ini dapat disimpulkan bahwa umur pemotongan 40 hari dengan pemupukan pupuk organik asal kotoran ayam sebanyak 400 gram/polybag menghasilkan jumlah stolon, panjang stolon, dan jumlah anakan terbaik.

\section{DAFTAR PUSTAKA}

Anis. SD.,M. A. Chozin,H. Soedarmadi and M. Ghulamadi. 2011. The efect Heights and interval of Defolation on produktivity and nutrien conten of brachiariahumidicola(Rendle) Schweich. Jurnal of Agronomy Indonesia 39(3):217-222
Anis,SD., D.A. Kaligis and S.P. Pengemanan. 2015. Integration of cattle and Koronivia grass Pasture. Underneath mature Coconuts in north Sulawesi, Indonesia . J. Livestock research for Rural Devolopment. No.7. vol. 27. http://Irrd.cipav.org.co/Irrd27/7/anis 27142.htm

Chotbang, J., S. Prajavkboonjetsada, S. Watananawin, A. Isuwan. 2008. Change in drymatter and nutritive composition of Brachiaria humidicola grown in Ban Thon soilseries.Int. J. Sci. Tech. 2(3): 551558.

Faizal,F.I. 2013. Pengaruh pupuk NPK terhadap rumput Brachiaria pada umur potong 60 hari SKRIPSI sarjana peternakan,Universitas Syah Kuala.

Ginting, S.P., A. Tarigan. 2007. Kualitas nutrisi Stenotaphrum secundatum dan Brachiaria humidicola pada Kambing. JITV. 11:273-279.

Harre,M.D.,S. Phengphet,T. Songsiri and E. Stern.2013. Efect Cutting interval on yield and quality of three $\mathrm{J}$. Tropical Gransland-Forases 1:84-86

Gomez, A.A and A.A. Gomez. 1995. Prosedur Statistik untuk Penelitian Pertanian. (Edisi II). Penerbit Universitas Indonesia.

Gorder,M.M., L.L.Manske and T.L. Stroh. 2005. Grazing Treatement effects on Vegetative tillering and soil rhizospheres of Western Wheatgrass. 2005 AnnualReport. Dickinson Research Extention Center. 1089 State Avenue.ND 58601.

Kurniawan,W.,Abdullah, M.A. Setiana 2017 Produksi dan kualitas rumput Brachiaria humidicoladifitaria 
decumben dan stenotaprum accundaty di bawah naungnsengol,karet dan kelapa sawit. Media peternakan. Vol 30(1):11-17

Kaligis,D. A., S.D.Anis. 2012. Longtern Evalution of some species of Tropical Pasture under Different Grazing Regime. Jurnal Lucrari zootehnie .57 (17):304-307.

Kusuma,M .E. 2015 Pengunaann dosis pupuk kotoran ternak ayam terhadap pertumbuhan dan produksi Brachiaria humidicolapada pemotongan pertama. Jurnal Ilmu hewan Tropical 4.(1) : 16-20

Simanungkalit. 2006. Pupuk organik dan pupuk hayati. Balai . Balai Penelitian Dan Pengembangan Pertanian.

Tropical farefes factsheet Brachia humidicola.

www.info/key/froves/media/html/B rachiariahumidicola diakses pada tanggal 18 Februari 2017. 
